OPEN ACCESS

Edited by:

Shuofeng Yuan,

The University of Hong Kong,

Hong Kong

Reviewed by:

Jun Wang,

University of Arizona, United States Shailesh Kumar Patel,

Chhattisgarh Kamdhenu

Vishwavidyalaya, India

*Correspondence:

Hadi M. Yassine

hyassine@qu.edu.qa

Ali H. Eid

ali.eid@qu.edu.qa

${ }^{\dagger}$ These authors have contributed equally to this work

Specialty section: This article was submitted to Viral Immunology, a section of the journal

Frontiers in Immunology

Received: 03 February 2021 Accepted: 15 March 2021

Published: 30 March 2021

Citation:

Wehbe Z, Wehbe M, Iratni R, Pintus G, Zaraket $H$, Yassine $H M$ and Eid $A H$ (2021) Repurposing Ivermectin for COVID-19: Molecular Aspects and

Therapeutic Possibilities.

Front. Immunol. 12:663586. doi: 10.3389/fimmu.2021.663586

\section{Repurposing Ivermectin for COVID-19: Molecular Aspects and Therapeutic Possibilities}

\author{
Zena Wehbe ${ }^{1 \dagger}$, Maya Wehbe ${ }^{2 \dagger}$, Rabah Iratni ${ }^{3}$, Gianfranco Pintus ${ }^{4,5}$, Hassan Zaraket ${ }^{6,7}$, \\ Hadi M. Yassine ${ }^{8^{*}}$ and Ali H. Eid ${ }^{9,10^{*}}$ \\ ${ }^{1}$ Department of Biology, Faculty of Arts and Sciences, American University of Beirut, Beirut, Lebanon, ${ }^{2}$ Department of \\ Internal Medicine, Basingstoke \& North Hampshire Hospital, Basingstoke, United Kingdom, ${ }^{3}$ Department of Biology, College \\ of Science, United Arab Emirates University, Al-Ain, United Arab Emirates, ${ }^{4}$ Department of Medical Laboratory Sciences, \\ College of Health Sciences, and Sharjah Institute for Medical Research, University of Sharjah, Sharjah, United Arab Emirates, \\ ${ }^{5}$ Department of Biomedical Sciences, University of Sassari, Sassari, Italy, ${ }^{6}$ Department of Experimental Pathology, \\ Immunology and Microbiology, Faculty of Medicine, American University of Beirut, Beirut, Lebanon, ${ }^{7}$ Center for Infectious \\ Disease Research (CIDR), Faculty of Medicine, American University of Beirut, Beirut, Lebanon, ${ }^{8}$ Biomedical Research Center, \\ Q.U. Health, Qatar University, Doha, Qatar, ${ }^{9}$ Department of Basic Medical Sciences, College of Medicine, Q.U. Health, Qatar \\ University, Doha, Qatar, ${ }^{10}$ Biomedical and Pharmaceutical Research Unit, Q.U. Health, Qatar University, Doha, Qatar
}

As of January 2021, SARS-CoV-2 has killed over 2 million individuals across the world. As such, there is an urgent need for vaccines and therapeutics to reduce the burden of COVID-19. Several vaccines, including mRNA, vector-based vaccines, and inactivated vaccines, have been approved for emergency use in various countries. However, the slow roll-out of vaccines and insufficient global supply remains a challenge to turn the tide of the pandemic. Moreover, vaccines are important tools for preventing the disease but therapeutic tools to treat patients are also needed. As such, since the beginning of the pandemic, repurposed FDA-approved drugs have been sought as potential therapeutic options for COVID-19 due to their known safety profiles and potential anti-viral effects. One of these drugs is ivermectin (IVM), an antiparasitic drug created in the 1970s. IVM later exerted antiviral activity against various viruses including SARS-CoV-2. In this review, we delineate the story of how this antiparasitic drug was eventually identified as a potential treatment option for COVID-19. We review SARS-CoV-2 lifecycle, the role of the nucleocapsid protein, the turning points in past research that provided initial 'hints' for IVM's antiviral activity and its molecular mechanism of action- and finally, we culminate with the current clinical findings.

Keywords: COVID-19, SARS-CoV-2, ivermectin, coronavirus, mechanism of action

\section{INTRODUCTION}

SARS-CoV-2 is a positive-sense RNA $\beta$-coronavirus, enclosing a capped polyadenylated $30 \mathrm{~kb}$ genome, which is the largest among RNA viruses (1). SARS-CoV-2 binds to the ACE2 enzyme on the surface of the target host cell by way of its outer spike protein (S) (2). The receptor-binding domain (RBD) on the S1 subunit interacts with the peptidase domain of ACE2. After partitioning 
into the host membrane, sequential enzymatic cleavages ultimately lead to the release of the viral genome into the cell (3).

The development of successful vaccines has been a priority in the pharmaceutical and scientific community (4). However, the time between the initial SARS-CoV-2 outbreak in December 2019 until the pharmaceutical companies began vaccine distribution spanned over a year (5). During this period, two million people have died worldwide, according to the World Health Organization (WHO). Moreover, the increasing mutations detected in the $\mathrm{S}$ protein have raised concerns that virus evolution might outpace vaccine rollout and the time needed to reach herd immunity $(6,7)$. Additionally, while vaccines are the main stay for halting the pandemic, it remains critical to develop therapeutics to treat patients and reduce the disease burden.

The drug ivermectin (IVM) has recently been shown to inhibit replication of SARS-CoV-2 in cell cultures (8). IVM is a widely used drug, known best for its antiparasitic properties in both veterinary and human medicine. It was first discovered in the 1970s by microbiologist Satoshi Omura and parasitologist William Campbell (9). Fifty years later, this same drug is suddenly at the forefront of the race against the current pandemic, namely via its unintentional inhibition of nuclear transport. It is important to understand and elucidate the 'journey' of how IVM emerged as a therapeutic agent against SARS-CoV-2, to follow this precedent and encourage repurposing available drugs for an increasing number of diseases. As such, we aim to highlight essential steps and components in the SARS-CoV-2 lifecycle, the significance of the nucleocapsid protein, the anecdotal evidence that hinted its potential as an anti-viral drug and its molecular mechanism of action. Finally, we summarize real-time results of current clinical trials.

\section{SARS-COV-2 LIFECYCLE}

\section{Initial Formation of the Replicase- Transcriptase Complexes}

The basis of the seemingly successful repurposing of IVM is rooted in the identification of important components encoded by the viral genome. The SARS-CoV-2 viral genome encodes nonstructural, structural, and accessory proteins. Its positive mRNA strand is translated within the host cell in order to, first, produce its own replication machinery, and second, to produce the structural components required to house viral progeny (10). Two-thirds of the genome code for two large polyproteins, ppla and pplab. Once formed, the polyproteins are subsequently cleaved into 16 individual non-structural proteins (nsps), which primarily provide enzymatic activity (11). Three nsps (1-3) are cleaved by papain-like proteases (PLpro), which itself is localized within nsp3, and the rest are cleaved by the main protease (3C-like protease, 3CLpro) on nsp5 (1). As such, translation of the viral PLpro and 3CLpro are essential for efficient reproduction of the virus. Once the nsps are available, they cooperatively form the replicase-transcriptase complexes (RTCs), which are required for the production of new virions (12). Some nsps (3,4 and 6) induce the development of double membranes from the endoplasmic reticulum (E.R.), Golgi apparatus (G.A.) or the ER-Golgi intermediate compartment (ERGIC), which serve as foci for viral genesis (12). Collectively, the rest of the nsps in the RTC include RNA polymerase, helicase, exoribonuclease, and methyltransferase, among many others. The exact mechanism of replicating its own genome is still under investigation. However, it is understood that negativesense intermediates are initially formed and then serve as templates for reproducing both genomic and sub-genomic positive-sense RNAs (13). A potential model for the RNA replication in SARS-CoV-2 has been postulated and it is based on homologous proteins in SARS-CoV-1 (10).

\section{The Importance of the Nucleocapsid Protein}

Structural proteins are highly conserved among the various genera of coronaviruses. They include the spike protein (S), the envelope protein $(\mathrm{E})$, the nucleocapsid protein $(\mathrm{N})$ and the membrane protein $(\mathrm{M})$. Once the structural proteins are synthesized, and the viral RNA is reproduced, the S, M and E become embedded within the previously formed double membranes from the host E.R. and eventually reach ERGIC. Meanwhile, the $\mathrm{N}$ protein which is tethered to the newly formed genome 'delivers' this RNA into S-M-E-embedded ERGIC membrane, leading to the formation of 'pockets' which eventually seal off into new virions (1). The interaction of $\mathrm{N}$ with the 3'-end of the viral genome is mediated via nsp3 (14), the largest subunit of the RTC. The nsp3 acidic ubiquitin-like $\mathrm{N}$ terminal domain (UbI1) binds to a serine- and arginine-rich domain in the $\mathrm{N}$ protein, thereby anchoring the viral genome to the RTC in order to facilitate RNA replication and, importantly, to eventually ensure the localization of the newly synthesized genome within the viral envelope (Hurst, Koetzner, \& Masters, 2013). Ultimately, the $\mathrm{N}$ protein is incorporated in the RNA helical structure, which underlies the envelope (15). Overall, the $\mathrm{N}$ protein enhances coronavirus transcription, interacts with the viral genome and with $\mathrm{M}$ in the viral envelope. Notably, inhibition of $\mathrm{N}$ was shown to greatly suppress viral replication, suggesting it is an essential factor in efficient virion production $(14,15)$. Interestingly, $\mathrm{N}$ is the highest expressed protein in infected cells, further corroborating its importance in the viral life cycle (15).

\section{THE SARS-COV-2 NUCLEOCAPSID PROTEIN ENTERS THE NUCLEUS}

\section{The Role of Importins}

Although RNA replication and translation occur in the cytosol, nuclear access is a key event in the infectious cycle of several viruses, including coronaviruses $(1,8)$. However, the entry of proteins into the nucleus is a tightly regulated process. To evade 
this limiting barrier, some viral proteins exploit the importin (IMP) superfamily of nuclear transporters to gain nuclear access (16). Nucleocytoplasmic trafficking is mediated via transmembrane nuclear pore complexes (NPCs) in the nucleus, composed of nucleoporin (NPR) subunits. A major class of NPRs known as FG-NPRs are distributed throughout the NPCs and enable nucleocytoplasmic transport due to their interaction with IMP transporters (17). The major IMP classes include IMP $\alpha$ and IMP $\beta$. Nuclear import is mainly mediated either by IMP $\beta$ s or by heterodimers of IMP $\alpha / \mathrm{IMP} \beta 1$ (17-19). For cytosolic protein cargo destined for nuclear import, IMPs, particularly IMP $\alpha$ proteins, recognize nuclear localization signals (NLS) on target cargo proteins, whereas IMP $\beta$ facilitates the actual transport via the NPCs (18). Efficient target binding to the IMPs/EXPs is further supported by Ran, the small monomeric GTPase (20). Active Ran causes dissociation of IMP $\beta$ from the importin/NLSprotein complex, releasing its tethered cargo into the nucleus (21). Thus, for a potential SARS-CoV-2 protein to reach the nucleus, it must contain an NLS, properly interact with IMP proteins and Ran must be activated.

\section{SARS-CoV-2 Nucleocapsid Protein Contains an Enhanced Nuclear Localization Signal}

As it happens, the SARS-CoV-2 N contains NLS motifs. Of great significance is the finding that NLS regions in the $\mathrm{N}$ gene of SARS-CoV viruses are highly variable compared to the NLS of other coronavirus clades (22). Importantly, these changes occurred during the recent evolution of the highly pathogenic coronavirus clades- including SARS-CoV-2 (22). Incidentally, the numerous nucleotide insertions and deletions within the NLS are associated with enhanced nuclear translocation. Three NLS motifs have been detected on the $\mathrm{N}$ of SARS-CoV-2, SARS-CoV, MERS-CoV and seasonal coronaviruses. Uniquely, as a result of the nucleotide variations found in SARS-CoV-2 and SARS-CoV1 , all three NLS motifs contain a distinctly higher overall positive charge among the peptides compared to the less virulent coronaviruses. The higher positive charge of NLS renders the entire $\mathrm{N}$ protein also more positively charged and subsequently enhances its efficacy (23). It has been previously corroborated in animal studies that the enhanced translocation of viral Ns to the nucleus results in more severe pathogenicity (24). Therefore, it is possible that these more positively charged Ns, which are characteristic of SARS-CoV-2, may be partially responsible for the associated detrimental effects.

\section{The Putative Role of the Nucleocapsid Protein Within the Nucleus}

It was previously shown that viral proteins that enter the nucleus might suppress host genes related to the anti-viral response, leading ultimately to increased pathogenicity (25). This may also be the case with SARS-CoV-2, as in vitro studies indicated that the SARS-CoV-2 NP could interact with dsDNA, possibly due to its high positive charge and the negative charge of DNA (26). Although the exact activity of the SARS-CoV-2 N within the nucleus has not been fully characterized, previous examination of several coronavirus Ns can offer insight (24).

The $\mathrm{N}$ of the coronavirus infectious bronchitis virus (IBV) was detected not only in the cytoplasm but also within the nucleolus. Nucleolus targeting was also shown with the SARSCoV-1 N (27). It is important to note that the presence of $\mathrm{N}$ in the nucleus was indispensable for the replication of IBV, highlighting that cytosolic activity was not sufficient. In another related coronavirus, mouse hepatitis virus (MHV), nuclear proteins were also implicated in its replication. MHV $\mathrm{N}$ was specifically detected in the nucleolus, which itself is formed during interphase of the cell cycle and allows formation of ribosomal RNA (rRNA) and ribosomal subunits. The reason for $\mathrm{N}$ targeting of the nucleolus is not entirely understood. However, it is possible that $\mathrm{N}$ associates with rRNAs, in order to 'reserve' their use for translation of subgenomic RNA. It was also shown in vitro that $\mathrm{N}$ transfection into cells resulted in multi-nucleate cells, indicating the delay of cytokinesis (24). This would provide favorable and prolonged conditions for the virus intracellularly to continue to synthesize its genome and sub-genome, translate its proteins and enable sufficient virion packaging. Moreover, $\mathrm{N}$ is proposed to dampen the host cell's antiviral transcriptional response within the nucleus (8). Nevertheless, confirming the presence SARS-CoV$2 \mathrm{~N}$ in the nucleolus and understanding its role would elucidate the pathogenicity of this virus.

$\mathrm{N}$ is an essential component of newly formed virions as it ensures a proper 'delivery' of the replicated viral RNA genome within the developing envelope $(28,29)$. Moreover, it is essential for proper viral RNA dependent RNA polymerase activity, as demonstrated in Influenza A (29). As such, targeting the activity of $\mathrm{N}$ would offer a potent antiviral activity against SARS-CoV-2. In fact, $\mathrm{N}$ was shown to be an effective anti-viral target against Influenza A. One of the useful properties of $\mathrm{N}$ is its numerous binding sites, which have been shown to accommodate various drugs $(29,30)$. For example, compounds which can target the tail-loop binding pocket abrogate $\mathrm{N}$ oligomerization, while the compound F66 binds to the RNA-binding groove of the protein and is associated with improved survival in animal models infected with Influenza A (29). Figure 1 illustrates how the N of SARS-CoV-2 facilitates virus replication and mitigates the host cell response, thus further strengthening its position as a promising target of anti-viral drugs.

\section{IVERMECTIN}

\section{The Discovery of Ivermectin}

IVM was originally discovered from organisms that were isolated from soil samples collected from the woods nearby to Kitasato Institute in Kawana, Japan. Fermentation products released by a bacterium from the soil, which was later classified as Streptomyces acermitilis, appeared to exhibit antiparasitic activity (specifically against Nematospiroides dubius). Purification and isolation of the bioactive compounds showed naturally occurring macrocyclic lactones, and these were 


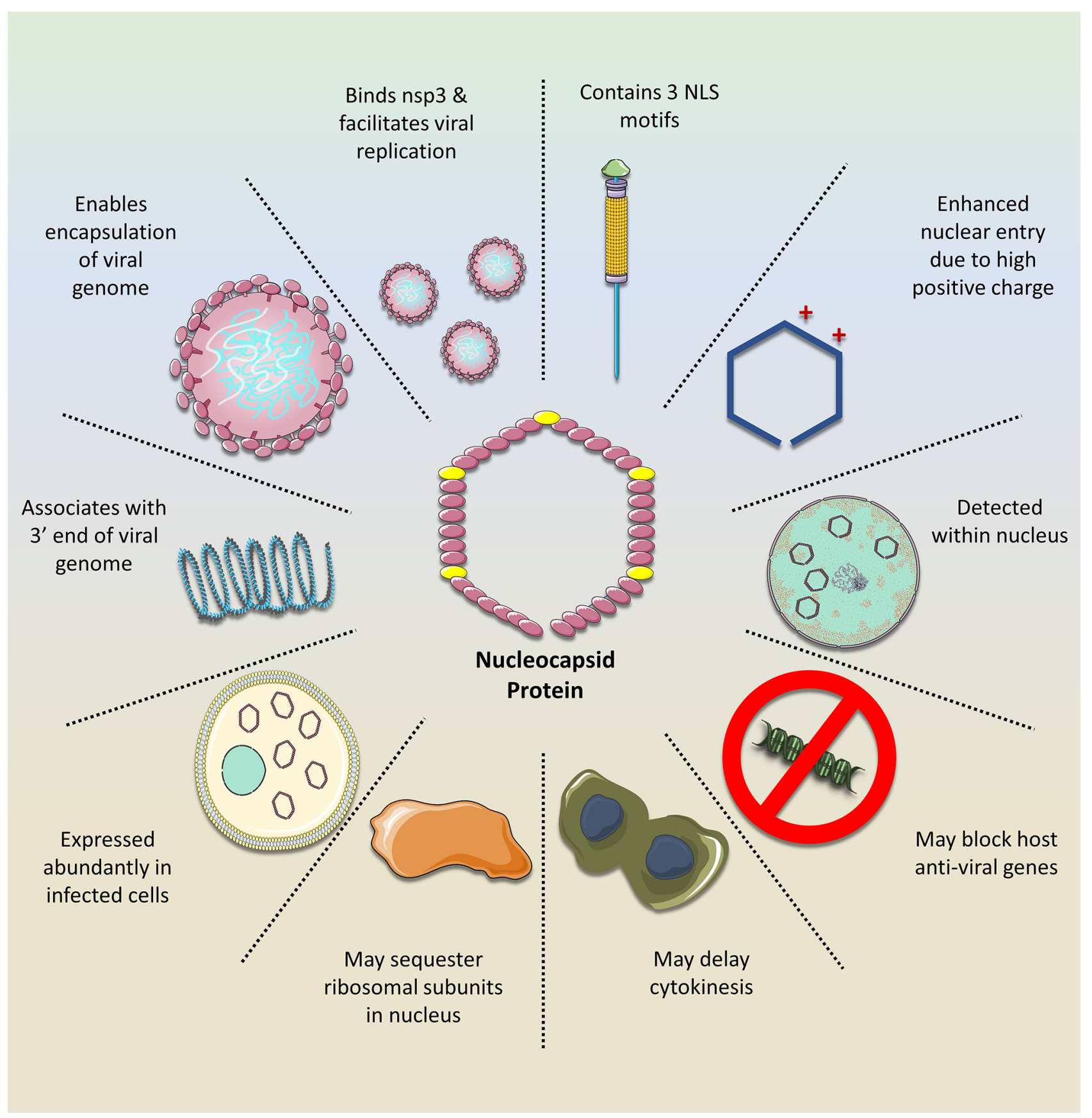

FIGURE 1 | The importance of the SARS-CoV-2 nucleocapsid protein (N). The N exerts numerous functions that facilitate viral replication while mitigating the host cell response. Owing to its NLS motifs, the protein retains a relatively high positive charge, compared to the $\mathrm{N}$ of other coronavirus clades. This enhances its transport into the nucleus where it may silence host anti-viral genes while sequestering ribosomal subunits, possibly for viral mRNA translation, as demonstrated with the $\mathrm{N}$ of other related viruses. Moreover, the $\mathrm{N}$ is important for stabilizing the interaction between the viral mRNA and nsp3 protein, which facilitates genome replication. In addition, it tethers the newly emerged viral RNA to the viral envelope, ultimately allowing for its encapsulation and formation of new viral progeny. Given these features and its abundance in the infected cell, it would be a promising drug target against SARS-CoV-2.

subsequently named avermectins. Avermectins are made up of four compounds, which exist as two variants: $A_{1}, A_{2}, B_{1}$, and $B_{2}$. Variants ' $A$ ' and ' $B$ ' indicate the presence of methoxy or hydroxyl groups, respectively, at the C5 position. Number ' 1 ' describes the double bond between $\mathrm{C}_{22}$ and $\mathrm{C}_{23}$. On the other hand, number ' 2 ' indicates the presence of hydrogen at $\mathrm{C}_{22}$ and a hydroxyl group at $\mathrm{C}_{23}$. $\mathrm{B}_{1}$ avermectins were proven to be most active on oral administration, and on this basis, IVM was chemically 
derived. IVM contains an 80:20 combination of 22,23-dihydroacvermectin $\mathrm{B}_{1 \mathrm{a}}$ and 22,23-dihydro-avermectin $\mathrm{B}_{1 \mathrm{~b}}$. Its antiparasitic effects are primarily caused by high-affinity irreversible binding to glutamate-gated chloride $\left(\mathrm{Cl}^{-}\right)$channels located on nerve and muscle cells of nematode, which leads to hyperpolarization $(9,31)$. Ultimately, the increased permeability to $\mathrm{Cl}^{-}$results in paralysis and death of the nematode (31).

As of yet, IVM has treated hundreds of millions of people with onchocerciasis, most commonly given at $150-200 \mu \mathrm{g} / \mathrm{kg}$ of body weight for one dose initially, and repeated at 6-12 monthly intervals as appropriate (32). Its use extends to a broad spectrum of parasitic nematodes on both oral and parenteral administration, and is also effective against arthropods, including lice (33).

Importantly, IVM was approved by the FDA for human use in 1987 (34). Its low toxicity and safety are attributed to the fact that its human target receptors are 'secluded' in the CNS, and IVM has not been shown to cross the blood-brain barrier. In addition, IVM displays a 100-fold greater affinity for parasitic $\mathrm{Cl}^{-}$ channels compared to the human homologs (35). Moreover, severe detrimental effects in humans were shown only in those who over-dosed using approximately $15.4 \mathrm{mg} / \mathrm{kg}$ body weight IVM, which is 77 times above the prescribed dose. This corroborates the advantage of repurposing drugs, as these medications have already been tested arduously and extensively to confirm their efficacy and safety, thereby decreasing the transit time from shelf to intake.

\section{Screening for Inhibitors of Nuclear Import}

The potential of IVM as an inhibitor of nuclear transport of viral proteins was initially suggested in 2011. Initially, Wagstaff and colleagues screened for nuclear import inhibitors, which block the interaction between IMPs and potential target cellular proteins (21). They randomly selected 480 compounds from LOPAC $^{1280}$ (Library of Pharmacologically Active Compounds; Sigma, St. Louis, MO). IVM surfaced as a drug that generally inhibits IMP activity (21). A year later, they confirmed that this apparent activity of IVM also inhibits nuclear transport of viral proteins HIV and Dengue virus in HeLa cells (36). Specifically, it was shown that GFP-tagged IMP was significantly reduced in the nucleus of HeLa cells after 3 hrs. of co-incubation with IVM (36). Moreover, the effect was unique to IMP $\alpha / \beta$ interactions and did not affect proteins bound only to IMP $\beta 1$. The importance of blocking the nuclear import of viral proteins emerged when it was later shown that IVM also prevented replication of HIV (36). As such, it surfaced as a possible repurposed drug, capable of preventing viral cargo from interacting with IMP $\alpha / \beta$ for nuclear import, with the potential to result in viral 'death' $(21,36)$.

Soon after, the effect of IVM against the nuclear import of viral proteins was further validated. For example, IVM prevented nuclear translocation of nsp5 in Dengue virus, West Nile virus, and influenza and inhibited transport of large tumor antigen ( $\mathrm{T}$ ag) in simian virus $(25,37,38)$. The Wagstaff et al., 2011 and 2012 studies were pivotal in providing much of the initial rationale for the recent consideration of IVM as a SARS-CoV2 antiviral agent. In fact, it was the same researchers who nine years later, in 2020, demonstrated that IVM inhibits SARSCoV-2 in vitro replication (8).

Given its efficacy in inhibiting nuclear import of other viral proteins, the anti-viral effect of IVM against SARS-CoV-2 was evaluated shortly after the pandemic erupted (8). Specifically, Vero/hSLAM cells were inoculated with SARS-CoV-2 isolate for 2 hrs., followed up with supplementation of $5 \mu \mathrm{M}$ of IVM. Within $24 \mathrm{hrs}$. after treatment, there was a $93 \%$ reduction of viral RNA in the supernatant and $99.8 \%$ reduction of cellular viral RNA, compared to controls. After 48 hrs., there was a further 5000 -fold reduction of viral RNA in the supernatant as well as the cell pellets, indicating that cells were essentially 'cleared' of SARS-CoV-2 (8). Although IVM possessed a potent antiviral activity $\left(\mathrm{IC}_{50}=\sim 2 \mu \mathrm{M}\right)$, no cytotoxicity was detected at any time points in this study (8).

\section{IVM Specifically Interacts With IMP $\alpha$}

IVM was shown to specifically inhibit IMP $\alpha / \beta$ mediated nuclear import required for replication of HIV-1 and Dengue virus, and therefore it was proposed as the potential mechanism by which it inhibits SARS-CoV-2 (36). Indeed, this baton was passed on, and a subsequent study verified the IVM-IMP $\alpha$ interaction in host cells (38). In fact, it was shown that IVM not only inhibits IMP $\alpha$ association with IMP $\beta$, but can even dissociate IMP $\alpha / \beta$ heterodimers (38). The specific binding target of IVM was identified, using CD spectroscopy, to be the alpha-helical rich 'armadillo' (ARM) domain of IMP $\alpha$. Moreover, as concentrations of IVM increased, alpha helices in the ARM domain became increasingly destabilized. No changes were detected in the structure of IMP $\beta$. They further verified that this observed effect on IMP $\alpha$ impaired its binding to NLScontaining nsp5 from Dengue Virus (38). As such, preventing $\mathrm{N}$ interaction with IMP $\alpha$, is a likely mechanism that contributes to IVM's ability to hinder SARS-CoV-2 in vitro replication (Figure 2).

\section{The Implications of Disrupting IMP $\alpha$ Activity for the Host Cells}

Because IVM emerged as a general inhibitor of IMP $\alpha$-dependent nuclear cargo, it is important to consider the implications this may have on host cell proteins and functions. However, any effect would likely be non-detrimental given the safety record of IVM over the past 50 years and its transient prescription for an acute disease (31).

Notably, expression levels of IMP $\alpha$ vary in a cell and developmental specific manner, particularly during differentiation processes (39). Animal knock-out studies for $i m p \alpha$, highlighted its essential role in reproductive organ development. Specifically, impa-/- mice developed lower reproductive organ function in females, including insufficient follicles' growth during the maturation stage in the ovaries, incomplete uterus construction, and reduced serum progesterone (40). Moreover, estrogen-responsive genes were also not efficiently expressed, indicating IMP $\alpha$ may be involved in hormonal regulation. Other cells like muscle stem cells underwent apoptosis and depletion (39). 


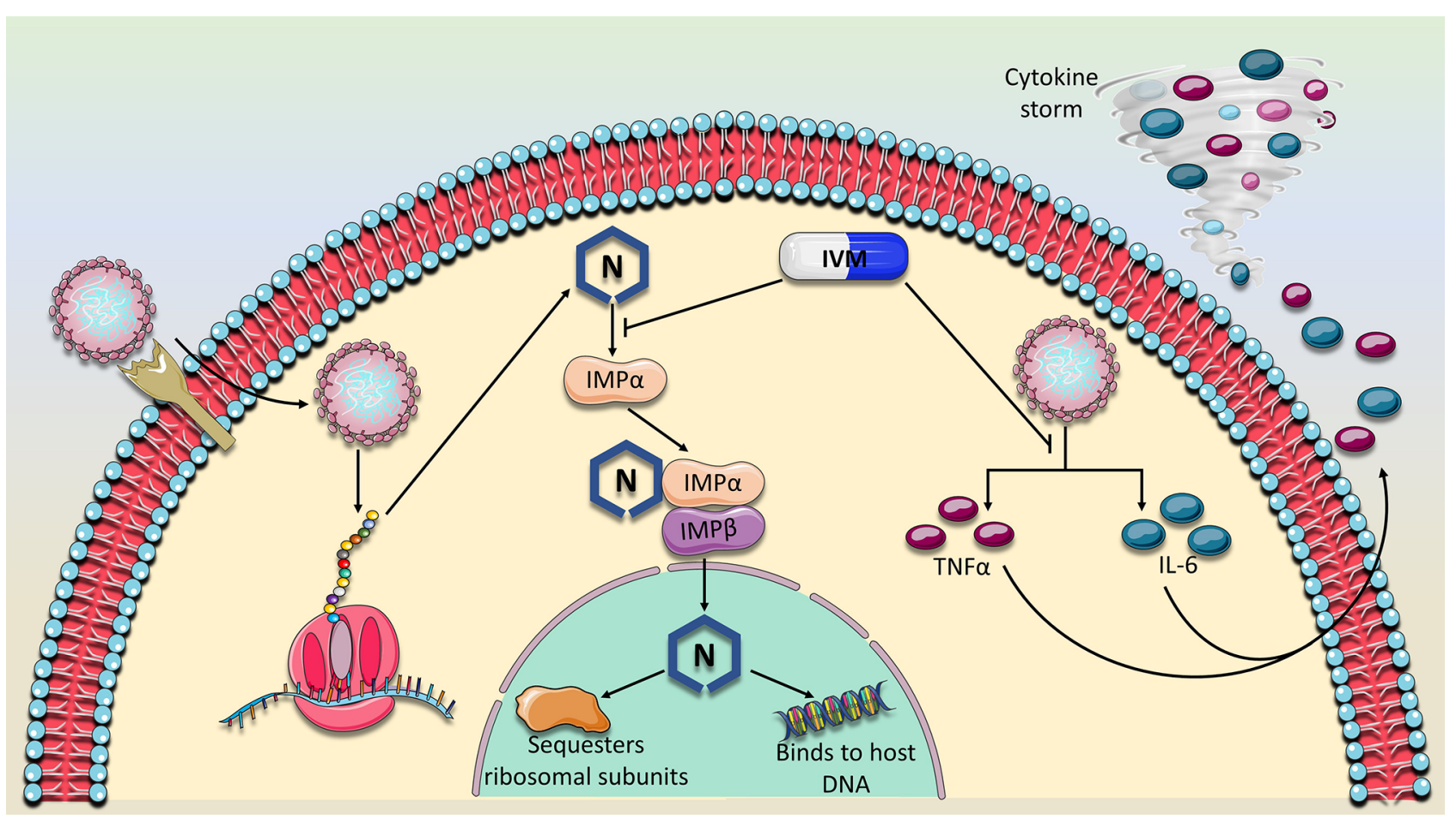

FIGURE 2 | Proposed mechanism of action of Ivermectin against SARS-CoV-2. IVM has previously been established as a nuclear import inhibitor by binding to and antagonizing the ability of the importin (IMP $\alpha$ ) to bind to its target cargo. Because the nucleocapsid ( $\mathrm{N}$ ) protein contains a nuclear localization signal, IVM is expected to prevent the binding of IMP $\alpha$ to the $\mathrm{N}$ binding site. Consequently, $\mathrm{N}$ would not perform its nuclear activity which is thought to suppress the host immune response and sequester ribosomal subunits, mechanisms which are thought to abrogate sufficient viral replication. In addition, the expression of two major cytokines, TNF $\alpha$ and IL-6 which drive the detrimental cytokine storm in COVID-19 patients were also shown to be dampened in the presence of IVM. As of yet, these two major mechanisms which involve viral replication and immune response suppression appear to characterize the main activities of IVM against SARS-CoV-2.

IVM was also shown to disrupt the oxygen regulatory mechanisms (41). Hypoxia-induced transcription factors (HIFs) regulate cellular adaptation to decreased oxygenation within the cell. Hypoxia renders the HIF subunit, HIF $\alpha$ stable and causes it to accumulate within the nucleus where it induces transcription of genes that may readjust oxygen levels. HIF $\alpha$ translocation into the nucleus requires nuclear import in an NLS-IMP $\alpha / \beta$ dependent manner. Indeed, it was shown that IVM results in decreased association between HIF $\alpha$ and IMP $\alpha$, preventing its path into the nucleus. Subsequently, nuclear HIF $\alpha$ and transcription of target oxygen-regulatory genes was reduced (41).

Pharmacokinetic studies conducted by MERCK show that IVM plasma concentrations peak after 4 hours, following $12 \mathrm{mg}$ doses in healthy human volunteers (42). Subsequently, it is metabolized in the liver and its break down products are mainly excreted in the feces over a period of 12 days. Its halflife is around $18 \mathrm{hrs}$. Moreover, it was shown that it does not bind permanently to its target proteins.

\section{Other Possible Modes of Antiviral Activity by IVM}

A recent molecular docking study demonstrated that in addition to IMP $\alpha$, IVM showed high binding affinity to the viral RNA- dependent RNA polymerase (RdRp) complexed with RNA helicase compared to other 10 viral targets included in the analysis (43). However, it was later shown that IVM does not bind to viral RdRp in both Zika virus (Z.V.) and Dengue virus (38). It remains to be identified if IVM may bind to RdRp in coronaviruses.

Other mechanisms of IVM action have also been identified (Figure 2). For example, it previously was shown to suppress the production of Interleukin-6 (IL-6) and Tumor Necrosis Factor alpha $(\mathrm{TNF} \alpha)$, two major components of the detrimental cytokine storm induced by SARS-CoV-2 (44). Moreover, a study in Syrian hamsters showed that IVM did not affect SARS-CoV-2 viral load but overall dramatically reduced IL-6/ IL-10 ratio and modulated infection outcomes (45). Specifically, hamsters that were inoculated with SARS-CoV-2 were subcutaneously injected with IVM $(0.4 \mathrm{mg} / \mathrm{kg}$ body weight). IVM reduced severity of clinical symptoms in males, but completely eliminated symptoms in females, which suggests a gender-specific effect of this drug and a factor that should be considered in clinical trials. The gender-specific modulation of IVM on cytokines was also apparent. While females displayed lower levels of cytokines such as IL-6, INF $\gamma$ and TNF $\alpha$, males on the other hand developed an enhanced production of INF $\gamma$. Notably, viral load in nasal and lung tissues, as well as viral 
replication rate were not altered in either gender after administration of IVM (45). This is in contrast to the finding that IVM significantly blocks viral replication in vitro and it may be attributed to the much higher dose of IVM that was used (8). However, it is important to note that the dose of IVM that was used on the cells $(5 \mu \mathrm{M})$ is approximately 50 -fold higher than the normal $C_{\max }$ associated with one dose of IVM $(200 \mu \mathrm{g} / \mathrm{kg})(46$, 47). Therefore, it is important to establish a dose-dependent effect of IVM on viral load and safety in human COVID-19 patients at various doses.

Further, IVM was shown to induce an elevated level of IL-6 and TNF $\alpha$ in onchocerciasis patients, two days after a single dose (150 $\mu \mathrm{g} / \mathrm{kg}$ body weight) (48). However, this was attributed to the destruction of the parasite microfilariae, which would usually not be a factor in COVID-19 patients.

Thus far, studies on IVM highlight that it remains important to identify the specific dose of IVM that may reduce viral load, without adverse effects, in humans and to understand if it will differentially affect male and female COVID-19 patients.

\section{Adverse Effects Reported in Animals and Humans in Previous Studies Using Ivermectin}

The direct toxic effects of IVM were first identified in animal studies, mainly as an antiparasitic treatment. The vast amount of evidence around the use of IVM exists using dose regimens of $150-200 \mu \mathrm{g} / \mathrm{kg}$ of body weight. Hence, the risks and associated side effects are mostly reported at these doses. Studies suggest the common adverse effects are rash, headache, nausea and dizziness, while transient tachycardia is rare and self-limiting (49). Other effects include ataxia, sweating, tremors, and in some cases, coma and death (50).

A retrospective study looking at residents of an extended care facility showed increased rates of death in patients treated with IVM for resistant scabies. These study results were criticized due to some significant limitations of the study, and therefore, the deaths of these residents could not be reliably attributed to the IVM. For example, there was no control of the lasting previous drugs used to treat the scabies, some of which are known for their toxic effects. Importantly, IVM's toxic effects are short term and are usually resolved (51).

Studies exploring the adverse event profiles of patients on high doses of IVM have also been conducted. Higher dose levels $(300-1000 \mu \mathrm{g} / \mathrm{kg}$ ) were administered to healthy individuals with head lice, as part of a double-blind and randomized trial, with adverse events reported as having no clinical or biochemical significance (50).

\section{CLINICAL TRIALS}

\section{The Effect of Ivermectin on SARS-CoV-2 Patients}

Soon after IVM emerged as a potential therapeutic agent, clinical trials on COVID-19 patients ensued. However, the available published data and ongoing clinical trials, which are summarized in Table 1, do not provide a clear and uniform understanding of the effect of IVM on COVID-19 patients. This is mainly due to small sample sizes $(n=12-203)$ and the lack of information specifying when exactly IVM is administered after testing positive for SARS-CoV-2 $(46,52-54)$. It is important to highlight how soon after testing positive the patient receives IVM, in addition to the degree of COVID-19 severity, in order to understand if the effect of the drug is dependent on time and symptom severity. Additionally, several studies are retrospective in which investigators examined past COVID-19 patients who were prescribed IVM, without proper placebo control groups $(46,53)$. Moreover, most of the studies utilize the antiparasitic effective dose for IVM $(0.2 \mathrm{mg} / \mathrm{kg}$ body weight), which is substantially less than the equivalent in vitro dose of IVM used against SARS-CoV-2 $(8,53,54)$. Nevertheless, the available data does indicate that IVM may, in fact, be effective against COVID-19.

One of the first published studies involved a randomized, controlled double-blind study on 72 hospitalized COVID-19 with mild symptoms (52). Patients that were admitted to the hospital within the last 7 days were either treated with IVM alone (12 mg for 5 days), IVM and doxycycline (12 mg for 1 day, 200 mg doxycycline on day 1 and $100 \mathrm{mg}$ doxycycline every $12 \mathrm{hrs}$. for days 2-6), or with placebo. The most significant effect of IVM was detected for the rate of viral clearance, measured by a negative rRT-PCR on nasopharyngeal swab. Specifically, the 5day IVM treatment group demonstrated the fastest rate of viral clearance (approximately 10 days; $\mathrm{p}<0.02$ ), compared to placebo (approximately 13 days). However, there was no significant difference between the groups for symptoms like cough, sore throat and fever and adverse drug effects (52). Limitations for this study include the exclusion of patients with underlying morbidities and lack of follow-up for mortality and ICU transfers after day 7.

Another recently published clinical study in Florida involved 280 hospital-admitted patients who developed COVID-19 during admission (53). However, it was based on a retrospective analysis of patients and therefore lacked adequate controls. Patients were grouped according to whether or not they received a single dose of IVM $(200 \mu \mathrm{g} / \mathrm{kg}$ body weight $)$ and standard care (hydroxychloroquine and azithromycin, unspecified dose) or those who only received standard care. It was not stated, though, at which day post-PCR testing that patients received the drug. The most prominent effect of IVM was the reduction in mortality in the treatment group $(15 \%$ mortality, $\mathrm{p}=0.03)$ compared to the control group $(25 \%$ mortality). Mortality was especially reduced in the severe subgroup of patients receiving oxygen support (38.\% mortality in IVM group, compared to $80.7 \%$ mortality in non-IVM group; $\mathrm{p}=0.001$ ). In fact, hospital stay was similar in both groups, as was the rate of viral clearance. However, data was lacking for clinical symptoms as it was not a main outcome (53). In contrast to the previous study, this trial included patients with comorbidities and no adverse drug events were reported. Although this study is limited because it is retrospective, it 


\begin{tabular}{|c|c|c|c|c|c|}
\hline Type of study & Treatment Groups & $\begin{array}{l}\text { Adverse Events due to } \\
\text { IVM }\end{array}$ & $\begin{array}{l}\text { Significant decrease } \\
\text { inBlood Biomarkers or } \\
\text { Clinical Symptoms }\end{array}$ & $\begin{array}{l}\text { Significant decrease in } \\
\text { viral clearance or viral } \\
\text { load }\end{array}$ & $\begin{array}{l}\text { Significant decrease in Mortality } \\
\text { and/or ICU transfer }\end{array}$ \\
\hline $\begin{array}{l}\text { (52) } \\
\text { - Randomized, Placebo-controlled trial } \\
\text { throat) }\end{array}$ & $\begin{array}{l}\text { Group 1: IVM (12 mg for } 5 \text { days) } \\
\mathbf{n = 2 4}\end{array}$ & None Reported & $\begin{array}{l}\downarrow \mathbf{C R P}(\mathbf{P}<0.02) \text {, day } \\
\mathbf{5 .} \\
\text { N.S* in clinical } \\
\text { symptoms by day } 7\end{array}$ & $\begin{array}{l}9.7 \text { days viral clearance } \\
\text { significantly reduced day } \\
7 \& 14 \text { compared to } \\
\text { placebo }(p<0.03)\end{array}$ & N/A \\
\hline \multirow[t]{2}{*}{ - No underlying comorbidities } & $\begin{array}{l}\text { Group 2: IVM ( } 12 \mathrm{mg} \text { once) } \\
\text { + doxycycline ( } 200 \mathrm{mg} \text { on day } 1 \\
100 \mathrm{mg} \text { every } 12 \mathrm{~h} \text { for the next } 4 \text { days). } \\
\mathbf{n}=\mathbf{2 4}\end{array}$ & None Reported & $\begin{array}{l}\text { N.S in clinical } \\
\text { symptoms by day } 7\end{array}$ & $\begin{array}{l}11.5 \text { days viral clearance } \\
\text { (N.S with Group 3) }\end{array}$ & $\mathrm{N} / \mathrm{A}$ \\
\hline & Group 3: Placebo control group, $\mathbf{n = 2 4}$ & None Reported & $\begin{array}{l}\text { No N.S in clinical } \\
\text { symptoms by day } 7\end{array}$ & $\begin{array}{l}12.7 \text { viral clearance (N.S with } \\
\text { Group 2) }\end{array}$ & $\mathrm{N} / \mathrm{A}$ \\
\hline $\begin{array}{l}\text { (53) } \\
\text { hospitalized patients with confirmed SARS- } \\
\text { CoV-2 during their admission, who had }\end{array}$ & $\begin{array}{l}\text { Group 1: IVM (200 } \mu \mathrm{g} / \mathrm{kg} \text { B.W and those } \\
\text { who had received a } 2 \text { nd dose at day } 7)+ \\
\text { hydroxychloroquine and/or azithromycin. } \\
\mathbf{n}=\mathbf{1 7 3}\end{array}$ & None Reported & N/A & 7 days (N.S) viral clearance & $\begin{array}{l}\mathbf{1 5} \% \text { of patients died }(\mathrm{P}=\mathbf{0 . 0 3 )} \\
\text { For the subset of patients receiving } \\
\text { oxygen support } \mathbf{3 8 . 8} \% \text { died } \\
(\mathbf{p}=\mathbf{0 . 0 0 1 )}\end{array}$ \\
\hline $\begin{array}{l}\text { received IVM. } \\
\text { - Included patients older than } 18 \text { and with } \\
\text { underlying morbidities. }\end{array}$ & $\begin{array}{l}\text { Group 2: Only provided standard care. } \\
\mathrm{n}=107\end{array}$ & None Reported & $N / A$ & 7 days (N.S) viral clearance & $\begin{array}{l}25.2 \% \text { of patients died } \\
\text { For the subset of patients receiving } \\
\text { oxygen support } \mathbf{8 0 . 7 \%} \text { died }\end{array}$ \\
\hline \multirow[t]{2}{*}{$\begin{array}{l}\text { (46) } \\
\text { hospitalized severe COVID-19 patients, who } \\
\text { had received IVM. Patients were compared } \\
\text { to those who did not receive IVM treatment. }\end{array}$} & $\begin{array}{l}\text { Group 1: IVM ( } 200 \mu \mathrm{g} / \mathrm{kg} \text {, single dose after } \\
12 \text { days since onset of symptoms) + } \\
\text { Immunosuppressant drugs (tocilizumab, } \\
\text { corticosteroids and/or anakinra), treated } \\
\text { with } \\
\mathbf{n}=\mathbf{1 3}\end{array}$ & None Reported & N.S in either & $N / A$ & N/A \\
\hline & $\begin{array}{l}\text { Group 2: Immunosuppressant drugs } \\
\text { (tocilizumab, corticosteroids and/or } \\
\text { anakinra) } \\
\mathbf{n = 1 3}\end{array}$ & None Reported & N.S in either & $\mathrm{N} / \mathrm{A}$ & $\mathrm{N} / \mathrm{A}$ \\
\hline $\begin{array}{l}\text { (54) Randomized, double-blind, placebo- } \\
\text { controlled trial using recently diagnosed } \\
\text { patients with mild SARS-CoV-2 and } 72 \mathrm{hrs} \text {. } \\
\text { within onset of fever or cough }\end{array}$ & $\begin{array}{l}\text { Group 1: IVM (400 } \mu \mathrm{g} / \mathrm{kg} \text { Body weight) } \\
\mathbf{n = 1 2}\end{array}$ & None & $\begin{array}{l}\text { N.S in blood } \\
\text { biomarkers } \\
\mathbf{5 0 \%} \text { reduced } \\
\text { hyposmia/anosmia. } \\
(\mathbf{P}<0.001)\end{array}$ & N.S & N/A \\
\hline $\begin{array}{l}\text { - Excluded patients with risk factors for } \\
\text { complicated disease }\end{array}$ & $\begin{array}{l}\text { Group 2: placebo } \\
\mathrm{n}=12\end{array}$ & None & N.S in either & N.S & $\mathrm{N} / \mathrm{A}$ \\
\hline \multirow[t]{2}{*}{$\begin{array}{l}\text { Ongoing Clinical Trial \# NCT04422561 } \\
\text { - Randomized, controlled trial for IVM as a } \\
\text { prophylactic treatment for asymptomatic } \\
\text { family members of new COVID-19 patients. }\end{array}$} & $\begin{array}{l}\text { Group 1: IVM (Ivermectin Tablets: } \\
40-60 \mathrm{~kg}(15 \mathrm{mg} / \text { day }) 60-80 \mathrm{~kg}(18 \mathrm{mg} / \text { day }) \\
>80 \mathrm{~kg}(24 \mathrm{mg} / \text { day) } \\
2 \text { doses } 72 \text { hours apart)) } \\
\mathbf{n}=\mathbf{2 0 3}\end{array}$ & $\begin{array}{l}5 \% \text { reported adverse } \\
\text { events (gastro- } \\
\text { intestinal G.I fatigue, } \\
\text { numbness) compared } \\
\text { to } 0 \% \text { control } \\
\text { (statistical significance } \\
\text { has not been } \\
\text { calculated) }\end{array}$ & $\mathrm{N} / \mathrm{A}$ & $\mathrm{N} / \mathrm{A}$ & $0 \%$ mortality \\
\hline & $\begin{array}{l}\text { Group 2: } \\
\mathrm{n}=101\end{array}$ & & N/A & $\mathrm{N} / \mathrm{A}$ & $0 \%$ mortality \\
\hline $\begin{array}{l}\text { Ongoing Clinical Trial \# NCT04343092 } \\
\text { - Interventional study, single group }\end{array}$ & $\begin{array}{l}\text { Group 1: Ivermectin }(0.2 \mathrm{mg} / \mathrm{kg} \text { body } \\
\text { weight) + Hydroxychloroquine } 400 \mathrm{mg} \text { at }\end{array}$ & $\begin{array}{l}0 \% \text { adverse events } \\
\text { related }\end{array}$ & V/A & $\mathrm{N} / \mathrm{A}$ & $\begin{array}{l}0 \% \text { mortality (statistical } \\
\text { significance not indicated) }\end{array}$ \\
\hline
\end{tabular}




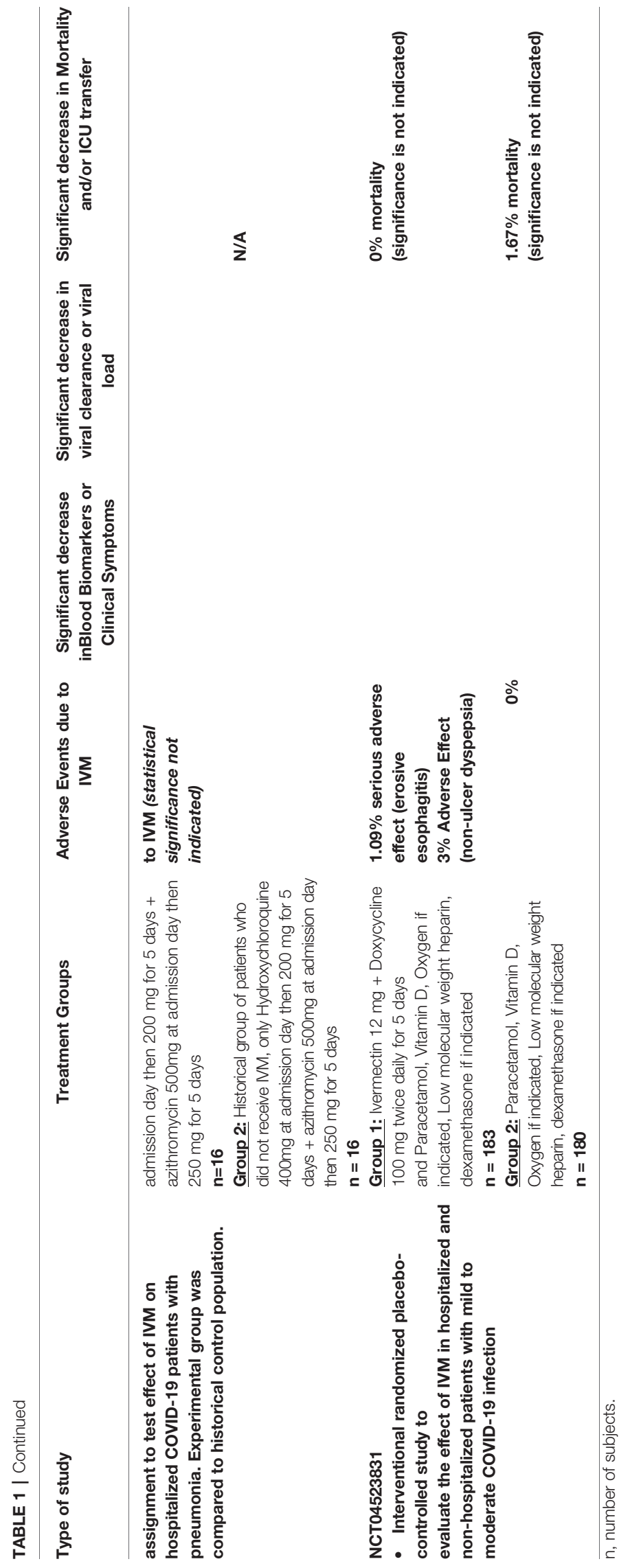

suggests that IVM may be beneficial in reducing mortality almost by one half, especially for patients receiving oxygen support. Nevertheless, it remains ambiguous as to how soon after testing positive for SARS-CoV-2, patients received IVM, which would have been an important guideline. The results of the few addition published IVM trials are summarized in Table $\mathbf{1}$.

There are currently around 50 clinical trials taking place registered on clinicaltrials.gov, which study the effect of IVM as a prophylactic or therapeutic drug (35). Five studies have completed testing at Phase 1,2 or 3 and three have posted their real-time results, which are included in Table 1. One of the most promising outcomes include 0\% mortality in COVID-19 patients who developed pneumonia (National Clinic Trial Number NCT04343092), however there is no report of an adequate control group and its corresponding rate of mortality. Another ongoing trial (NCT04523831) on COVID-19 hospitalized and non-hospitalized patients also demonstrated $0 \%$ mortality, in the IVM group, compared to $1.67 \%$ mortality in the control group. Like published studies, ongoing clinical trials also do not present thorough outcomes and the significance statistics are still lacking. As such, more trials are needed which include proper placebo control groups, testing of various doses and records of numerous outcomes.

\section{Ivermectin Compared to Other Anti-SARS-CoV-2 Drugs}

In addition to IVM, many clinical trials have been conducted to test drugs for COVID-19, many of which have been concluded (47). Most of these medications did not result in significantly improved outcomes, however a few drugs were associated with slightly beneficial effects.

Remdesivir (RMV) has previously been shown to target the viral RNA dependent RNA polymerase in SARS-CoV-1 (55). In the context of SARS-CoV-2, RMV prescribed once daily for 10 days (200 mg day $1,100 \mathrm{mg}$ days 9-10), showed a survival benefit by days 15 and 28 in patients who did not require oxygen support (56). On the other hand, a large global study by the WHO did not find any clinical benefit for RMV (57). However, an in vitro study suggests a possible synergistic effect of combined RMV and IVM. Specifically, $\mathrm{EC}_{50}$ of approximately $2.3 \mu \mathrm{M}$ IVM and $1.9 \mu \mathrm{M}$ RMV were shown to disrupt viral cytopathic activity (58). Because RMV is FDA-approved for the treatment of COVID-19, it is warranted to explore its effect in combination with IVM in clinical trials.

Dexamethasone (6 $\mathrm{mg}$ for 10 days) decreased mortality only in severe cases requiring oxygen and mechanical ventilation but was ineffective for mild cases and did not result in any adverse effects (59). Interestingly, a clinical trial (NCT04425863) involving a combined therapy of IVM $(0.6 \mathrm{mg} / \mathrm{mL}$ solution), dexamethasone (4 $\mathrm{mg}$ injection), aspirin (250 $\mathrm{mg}$ tablets) and enoxaparin (injection) did indicate a favorable outcome. All patients with mild COVID-19 symptoms ( $n=135)$ fully recovered and their symptoms did not worsen. Of those who entered the study displaying severe symptoms $(n=31)$, one patient perished.

The use of convalescent plasma is also not entirely promising as preliminary analysis based on 1873 reported deaths among 
10,406 randomized patients, shows no significant difference in the primary endpoint of 28 -day mortality ( $18 \%$ convalescent plasma vs. $18 \%$ usual care alone, $\mathrm{p}=0.34$ ). Although some early studies showed some clinical benefits for convalescent plasma in COVID-19 patients (47), a recent press release from the largest randomized clinical trial, known as the 'RECOVERY Trial', revealed otherwise (60). The investigators concluded no evidence of benefit for convalescent plasma in treatment of COVID-19, whereby the 28-day mortality did not differ significantly between the treatment and the control groups. Recently two clinical trials showed that monoclonal antibodies against the spike protein can disrupt progression of early COVID-19 infection $(61,62)$. However, this type of therapeutic remains very expensive and largely unavailable.

Finally, a recent study, still awaiting peer-review, demonstrated that treatment with the IL- 6 receptor antagonists, tocilizumab and sarilumab, improved the clinical outcome including survival in critically ill COVID-19 patients (63). However, these drugs remain expensive and not widely available especially in poor and developing countries.

\section{CONCLUDING REMARKS AND PERSPECTIVES}

The available data from IVM clinical trials lack uniformity and have not established the optimal anti-viral dose. However, the evidence does support its safety and efficacy in improving survival rates, especially compared to the other aforementioned drugs. It is important to note that past research has demonstrated the importance of combined, rather than anti-viral monotherapy. Indeed, the use of a single drug does not efficiently suppress longterm replication of the virus (64). As evident by the ongoing clinical trials for the treatment of COVID-19, the most efficient decrease in mortality $(0 \%)$ was largely a result of multiple prescribed drugs including IVM, hydroxychloroquine and azithromycin or IVM and doxycyline Table 1. Given the wide use of numerous drugs to treat COVID-19 patients, it remains imperative to explore the optimal combination of various therapies.

Notably, the clinical outcomes upon prescribing IVM on its own did not result in significantly improved outcomes for

\section{REFERENCES}

1. Wang Y, Grunewald M, Perlman S. Coronaviruses: An Updated Overview of Their Replication and Pathogenesis. Methods Mol Biol (2020) 2203:1-29. doi: 10.1007/978-1-0716-0900-2_1

2. Hoffmann M, Kleine-Weber H, Schroeder S, Krüger N, Herrler T, Erichsen S, et al. SARS-CoV-2 Cell Entry Depends on ACE2 and TMPRSS2 and Is Blocked by a Clinically Proven Protease Inhibitor. Cell (2020) 2:271-80. doi: 10.1016/j.cell.2020.02.052

3. Lu G, Wang Q, Gao GF. Bat-to-human: spike features determining 'host jump' of coronaviruses SARS-CoV, MERS-CoV, and beyond. Trends Microbiol (2015) 23(8):468-78. doi: 10.1016/j.tim.2015.06.003

4. Mathew S, Faheem M, Hassain NA, Benslimane FM, Thani AAA, Zaraket H, et al. Platforms Exploited for SARS-CoV-2 Vaccine Development. Vaccines (Basel) (2020) 9(1):11. doi: 10.3390/vaccines9010011
COVID-19 patients and nor should it be particularly encouraged (54). In fact, cross-resistance to other medications may be induced as a result of selective pressure resulting from a single medication (64). This may be a likely event as RNA viruses are well noted for their pronounced capacity for mutations, a finding which has already been established also for SARS-CoV-2 (65). Therefore, although IVM may contribute to the suppression of SARS-CoV-2 replication, it is important not to dismiss the risk of selecting for highly pathological and resistant viral strains when using a sole medication. That said, in a recent clinical trial that we have just concluded and is under review, we show that a single dose of IVM can significantly reduce the viral load in asymptomatic SARS-CoV-2 positive subjects. However, in these subjects, zinc and vitamin $C$ were concomitantly used.

The available data thus far suggests a favorable outcome when using IVM in specific doses and in particular drug combinations. It remains imperative to establish the most effective doses, combination, and timing of drug administration as it may largely determine the therapeutic outcome. Although vaccines are currently being distributed, they do not guarantee complete protection against SARS-CoV-2. Therefore, it is important to establish therapeutic alternatives in the event that viral reinfection occurs. Given the promising emerging clinical data from IVM studies and the unprecedented public health threat that the pandemic poses, it is critical that further specific and well-designed studies are carried out to validate the therapeutic potential of IVM.

\section{AUTHOR CONTRIBUTIONS}

AE generated the concept. ZW and MW wrote the first draft. All authors revised the manuscript and approved it before submission. HY generated funding.

\section{FUNDING}

This study was supported by Qatar University Grants \# QUCGBRC-20_21 and QUHI-BRC-20/21-1.

5. Chen N, Zhou M, Dong X, Qu J, Gong F, Han Y, et al. Epidemiological and clinical characteristics of 99 cases of 2019 novel coronavirus pneumonia in Wuhan, China: a descriptive study. Lancet (2020) 395(10223):507-13. doi: 10.1016/S0140-6736(20)30211-7

6. Chen J, Wang R, Wang M, Wei GW. Mutations Strengthened SARS-CoV-2 Infectivity. J Mol Biol (2020) 432(19):5212-26. doi: 10.1016/j.jmb.2020.07.009

7. Singh PK, Kulsum U, Rufai SB, Mudliar SR, Singh S. Mutations in SARSCoV-2 Leading to Antigenic Variations in Spike Protein: A Challenge in Vaccine Development. J Lab Physicians (2020) 12(2):154-60. doi: 10.1055/s0040-1715790

8. Caly L, Druce JD, Catton MG, Jans DA, Wagstaff KM. The FDA-approved drug ivermectin inhibits the replication of SARS-CoV-2 in vitro. Antiviral Res (2020) 178:104787. doi: 10.1016/j.antiviral.2020.104787

9. Crump A, Ōmura S. Ivermectin, 'wonder drug' from Japan: the human use perspective. Proc Jpn Acad Ser B Phys Biol Sci (2011) 87(2):13-28. doi: $10.2183 /$ pjab.87.13 
10. Romano M, Ruggiero A, Squeglia F, Maga G, Berisio R. A Structural View of SARS-CoV-2 RNA Replication Machinery: RNA Synthesis, Proofreading and Final Capping. Cells (2020) 9(5):1267. doi: 10.3390/cells9051267

11. Ziebuhr J, Snijder EJ, Gorbalenya AE. Virus-encoded proteinases and proteolytic processing in the Nidovirales. J Gen Virol (2000) 81(Pt 4):85379. doi: 10.1099/0022-1317-81-4-853

12. Cong Y, Ulasli M, Schepers H, Mauthe M, V'kovski P, Kriegenburg F, et al. Nucleocapsid Protein Recruitment to Replication-Transcription Complexes Plays a Crucial Role in Coronaviral Life Cycle. J Virol (2020) 94(4):e01925-19. doi: 10.1128/JVI.01925-19

13. Sawicki SG, Sawicki DL. A new model for coronavirus transcription. Adv Exp Med Biol (1998) 440:215-9. doi: 10.1007/978-1-4615-5331-1_26

14. McBride R, van Zyl M, Fielding BC. The coronavirus nucleocapsid is a multifunctional protein. Viruses (2014) 6(8):2991-3018. doi: 10.3390/ v6082991

15. Savastano A, Ibáñez de Opakua A, Rankovic M, Zweckstetter M. Nucleocapsid protein of SARS-CoV-2 phase separates into RNA-rich polymerase-containing condensates. Nat Commun (2020) 11(1):6041. doi: 10.1038/s41467-020-19843-1

16. Fulcher AJ, Jans DA. Regulation of nucleocytoplasmic trafficking of viral proteins: an integral role in pathogenesis? Biochim Biophys Acta (2011) 1813 (12):2176-90. doi: 10.1016/j.bbamcr.2011.03.019

17. Rout MP, Aitchison JD. Pore relations: nuclear pore complexes and nucleocytoplasmic exchange. Essays Biochem (2000) 36:75-88. doi: 10.1042/ bse 0360075

18. Fried H, Kutay U. Nucleocytoplasmic transport: taking an inventory. Cell Mol Life Sci (2003) 60(8):1659-88. doi: 10.1007/s00018-003-3070-3

19. Goldfarb DS, Corbett AH, Mason DA, Harreman MT, Adam SA. Importin alpha: a multipurpose nuclear-transport receptor. Trends Cell Biol (2004) 14 (9):505-14. doi: 10.1016/j.tcb.2004.07.016

20. Weis K. Regulating access to the genome: nucleocytoplasmic transport throughout the cell cycle. Cell (2003) 112(4):441-51. doi: 10.1016/s0092-8674(03)00082-5

21. Wagstaff KM, Rawlinson SM, Hearps AC, Jans DA. An AlphaScreen ${ }^{\circledR}$-based assay for high-throughput screening for specific inhibitors of nuclear import. J Biomol Screen (2011) 16(2):192-200. doi: 10.1177/1087057110390360

22. Gussow AB, Auslander N, Faure G, Wolf YI, Zhang F, Koonin EV. Genomic determinants of pathogenicity in SARS-CoV-2 and other human coronaviruses. Proc Natl Acad Sci USA (2020) 117(26):15193-9. doi: 10.1073/pnas.2008176117

23. Cokol M, Nair R, Rost B. Finding nuclear localization signals. EMBO Rep (2000) 1(5):411-5. doi: 10.1093/embo-reports/kvd092

24. Wurm T, Chen H, Hodgson T, Britton P, Brooks G, Hiscox JA. Localization to the nucleolus is a common feature of coronavirus nucleoproteins, and the protein may disrupt host cell division. J Virol (2001) 75(19):9345-56. doi: 10.1128/JVI.75.19.9345-9356.2001

25. Gotz V, Magar L, Dornfeld D, Giese S, Pohlmann A, Hoper D, et al. Influenza A viruses escape from MxA restriction at the expense of efficient nuclear vRNP import. Sci Rep (2016) 6:23138. doi: 10.1038/srep23138

26. Zeng W, Liu G, Ma H, Zhao D, Yang Y, Liu M, et al. Biochemical characterization of SARS-CoV-2 nucleocapsid protein. Biochem Biophys Res Commun (2020) 527(3):618-23. doi: 10.1016/j.bbrc.2020.04.136

27. You JH, Reed ML, Hiscox JA. Trafficking motifs in the SARS-coronavirus nucleocapsid protein. Biochem Biophys Res Commun (2007) 358(4):1015-20. doi: 10.1016/j.bbrc.2007.05.036

28. Hurst KR, Koetzner CA, Masters PS. Characterization of a critical interaction between the coronavirus nucleocapsid protein and nonstructural protein 3 of the viral replicase-transcriptase complex. J Virol (2013) 87(16):9159-72. doi: 10.1128/JVI.01275-13

29. Hu Y, Sneyd H, Dekant R, Wang J. Influenza A Virus Nucleoprotein: A Highly Conserved Multi-Functional Viral Protein as a Hot Antiviral Drug Target. Curr Top Med Chem (2017) 17(20):2271-85. doi: 10.2174/ 1568026617666170224122508

30. Lin SM, Lin SC, Hsu JN, Chang CK, Chien CM, Wang YS, et al. StructureBased Stabilization of Non-native Protein-Protein Interactions of Coronavirus Nucleocapsid Proteins in Antiviral Drug Design. J Med Chem (2020) 63 (6):3131-41. doi: 10.1021/acs.jmedchem.9b01913

31. Ikeda T. Pharmacological effects of ivermectin, an antiparasitic agent for intestinal strongyloidiasis: its mode of action and clinical efficacy. Nihon Yakurigaku Zasshi (2003) 122(6):527-38. doi: 10.1254/fpj.122.527
32. González Canga A, Sahagún Prieto AM, Diez Liébana MJ, Fernández Martínez N, Sierra Vega M, García Vieitez JJ. The pharmacokinetics and interactions of ivermectin in humans-a mini-review. AAPS J (2008) 10(1):426. doi: 10.1208/s12248-007-9000-9

33. Schröder J, Swan GE, Soll MD, Hotson IK. Efficacy of ivermectin against ectoparasites of cattle in South Africa. J S Afr Vet Assoc (1985) 56(1):31-5.

34. Juarez M, Schcolnik-Cabrera A, Dueñas-Gonzalez A. The multitargeted drug ivermectin: from an antiparasitic agent to a repositioned cancer drug. Am J Cancer Res (2018) 8(2):317-31.

35. Kaur H, Shekhar N, Sharma S, Sarma P, Prakash A, Medhi B. Ivermectin as a potential drug for treatment of COVID-19: an in-sync review with clinical and computational attributes. Pharmacol Rep (2021). doi: 10.1007/s43440-02000195-y

36. Wagstaff KM, Sivakumaran H, Heaton SM, Harrich D, Jans DA. Ivermectin is a specific inhibitor of importin $\alpha / \beta$-mediated nuclear import able to inhibit replication of HIV-1 and dengue virus. Biochem J (2012) 443(3):851-6. doi: 10.1042/BJ20120150

37. Tay MY, Fraser JE, Chan WK, Moreland NJ, Rathore AP, Wang C, et al. Nuclear localization of dengue virus (DENV) 1-4 non-structural protein 5; protection against all 4 DENV serotypes by the inhibitor Ivermectin. Antiviral Res (2013) 99(3):301-6. doi: 10.1016/j.antiviral.2013.06.002

38. Yang SNY, Atkinson SC, Wang C, Lee A, Bogoyevitch MA, Borg NA, et al. The broad spectrum antiviral ivermectin targets the host nuclear transport importin $\alpha / \beta 1$ heterodimer. Antiviral Res (2020) 177:104760. doi: 10.1016/ j.antiviral.2020.104760

39. Oka M, Yoneda Y. Importin $\alpha$ : functions as a nuclear transport factor and beyond. Proc Jpn Acad Ser B Phys Biol Sci (2018) 94(7):259-74. doi: 10.2183/ pjab.94.018

40. Moriyama T, Nagai M, Oka M, Ikawa M, Okabe M, Yoneda Y. Targeted disruption of one of the importin $\alpha$ family members leads to female functional incompetence in delivery. FEBS J (2011) 278(9):1561-72. doi: 10.1111/j.17424658.2011.08079.x

41. Kosyna FK, Nagel M, Kluxen L, Kraushaar K, Depping R. The importin $\alpha /$ $\beta$-specific inhibitor Ivermectin affects HIF-dependent hypoxia response pathways. Biol Chem (2015) 396(12):1357-67. doi: 10.1515/hsz-20150171

42. TABLETS; STROMECTOL ${ }^{\circledR}($ IVERMECTIN) (MERCK). Available at: https:// www.merck.com/product/usa/pi_circulars/s/stromectol/stromectol_pi.pdf.

43. Sen Gupta PS, Biswal S, Panda SK, Ray AK, Rana MK. Binding mechanism and structural insights into the identified protein target of COVID-19 and importin- $\alpha$ with. J Biomol Struct Dyn (2020) 1-10. doi: 10.1080/ 07391102.2020.1839564

44. Zhang X, Song Y, Ci X, An N, Ju Y, Li H, et al. Ivermectin inhibits LPSinduced production of inflammatory cytokines and improves LPS-induced survival in mice. Inflamm Res (2008) 57(11):524-9. doi: 10.1007/s00011-0088007-8

45. de Melo GD, Lazarini F, Larrous F, Feige L, Kergoat L, Marchio A, et al. AntiCOVD-19 efficacy of ivermectin in the golden hamster. BioRxiv (2020). doi: 10.1101/2020.11.21.392639

46. Camprubí D, Almuedo-Riera $\mathrm{A}$, Martí-Soler $\mathrm{H}$, Soriano $\mathrm{A}$, Hurtado JC, Subirà C, et al. Lack of efficacy of standard doses of ivermectin in severe COVID-19 patients. PloS One (2020) 15(11):e0242184. doi: 10.1371/journal.pone.0242184

47. Kaddoura M, AlIbrahim M, Hijazi G, Soudani N, Audi A, Alkalamouni H, et al. COVID-19 Therapeutic Options Under Investigation. Front Pharmacol (2020) 11:1196. doi: 10.3389/fphar.2020.01196

48. Njoo FL, Hack CE, Oosting J, Luyendijk L, Stilma JS, Kijlstra A. C-reactive protein and interleukin-6 are elevated in onchocerciasis patients after ivermectin treatment. J Infect Dis (1994) 170(3):663-8. doi: 10.1093/infdis/ 170.3.663

49. Guzzo CA, Furtek CI, Porras AG, Chen C, Tipping R, Clineschmidt CM, et al. Safety, tolerability, and pharmacokinetics of escalating high doses of ivermectin in healthy adult subjects. J Clin Pharmacol (2002) 42(10):112233. doi: $10.1177 / 009127002401382731$

50. Seward RL. Reactions in dogs given ivermectin. J Am Vet Med Assoc (1983) 183(5):493.

51. Alexander ND, Bockarie MJ, Kastens WA, Kazura JW, Alpers MP. Absence of ivermectin-associated excess deaths. Trans R Soc Trop Med Hyg (1998) 92 (3):342. doi: 10.1016/s0035-9203(98)91035-5 
52. Ahmed S, Karim MM, Ross AG, Hossain MS, Clemens JD, Sumiya MK, et al. A five-day course of ivermectin for the treatment of COVID-19 may reduce the duration of illness. Int J Infect Dis (2020) 103:214-6. doi: 10.1016/ j.ijid.2020.11.191

53. Rajter JC, Sherman MS, Fatteh N, Vogel F, Sacks J, Rajter JJ. Use of Ivermectin Is Associated With Lower Mortality in Hospitalized Patients With Coronavirus Disease 2019: The Ivermectin in COVID Nineteen Study. Chest (2021) 159(1):85-92. doi: 10.1016/j.chest.2020.10.009

54. Chaccour C, Ruiz-Castillo P, Richardson MA, Moncunill G, Casellas A, CarmonaTorre F, et al. The SARS-CoV-2 Ivermectin Navarra-ISGlobal Trial (SAINT) to Evaluate the Potential of Ivermectin to Reduce COVID-19 Transmission in low risk, non-severe COVID-19 patients in the first 48 hours after symptoms onset: A structured summary of a study protocol for a randomized control pilot trial. Trials (2020) 21(1):498. doi: 10.1186/s13063-020-04421-z

55. Agostini ML, Andres EL, Sims AC, Graham RL, Sheahan TP, Lu X, et al. Coronavirus Susceptibility to the Antiviral Remdesivir (GS-5734) Is Mediated by the Viral Polymerase and the Proofreading Exoribonuclease. mBio (2018) 9 (2):e00221-18. doi: 10.1128/mBio.00221-18

56. Beigel JH, Tomashek KM, Dodd LE, Mehta AK, Zingman BS, Kalil AC, et al. Remdesivir for the Treatment of Covid-19 - Final Report. N Engl J Med (2020) 383(19):1813-26. doi: 10.1056/NEJMoa2007764

57. Pan H, Peto R, Henao-Restrepo AM, Preziosi MP, Sathiyamoorthy V, Abdool Karim Q, et al. Repurposed Antiviral Drugs for Covid-19 - Interim WHO Solidarity Trial Results. N Engl J Med (2020) 384:497-511. doi: 10.1056/NEJMoa2023184

58. Jeffreys L, Pennington SH, Duggan J, Breen A, Jinks J, Ardrey A, et al. Remdesivir-Ivermectin combination displays synergistic interaction with improved in vitro antiviral activity against SARS-CoV-2. (2020). doi: $10.1101 / 2020.12 .23 .424232$

59. Horby P, Lim WS, Emberson JR, Mafham M, Bell JL, Linsell L, et al. Dexamethasone in Hospitalized Patients with Covid-19 - Preliminary Report. N Engl J Med (2020) 384:693-704. doi: 10.1056/NEJMoa2021436
60. Recovery Trial Closes Recruitment to Convalescent Plasma Treatment for Patients Hospitalised with COVID-19. Nuffield Department of Population Health. University of Oxford (2021).

61. Weinreich DM, Sivapalasingam S, Norton T, Ali S, Gao H, Bhore R, et al. REGN-COV2, a Neutralizing Antibody CocktailOutpatients with Covid-19. N Engl J Med (2021) 384(3):238-51. doi: 10.1056/NEJMoa 2035002

62. Chen P, Nirula A, Heller B, Gottlieb RL, Boscia J, Morris J, et al. SARS-CoV-2 Neutralizing Antibody LY-CoV555 in Outpatients with Covid-19. N Engl J Med (2021) 384(3):229-37. doi: 10.1056/NEJMoa2029849

63. Gordon AC, Mouncey PR, Al-Beidh F, Rowan KM, Nichol AD, Arabi YM, et al. Interleukin-6 Receptor Antagonists in Critically Ill Patients with Covid19 -Preliminary report. N Engl J Med (2021). doi: 10.1056/NEJMoa2100433

64. Larder BA. Viral resistance and the selection of antiretroviral combinations. J Acquir Immune Defic Syndr Hum Retrovirol (1995) 10(Suppl 1):S28-33. doi: 10.1097/00042560-199510001-00007

65. Santos IA, Grosche VR, Bergamini FRG, Sabino-Silva R, Jardim ACG. Antivirals Against Coronaviruses: Candidate Drugs for SARS-CoV-2 Treatment? Front Microbiol (2020) 11:1818. doi: 10.3389/fmicb.2020.01818

Conflict of Interest: The authors declare that the research was conducted in the absence of any commercial or financial relationships that could be construed as a potential conflict of interest.

Copyright ( () 2021 Wehbe, Wehbe, Iratni, Pintus, Zaraket, Yassine and Eid. This is an open-access article distributed under the terms of the Creative Commons Attribution License (CC BY). The use, distribution or reproduction in other forums is permitted, provided the original author(s) and the copyright owner(s) are credited and that the original publication in this journal is cited, in accordance with accepted academic practice. No use, distribution or reproduction is permitted which does not comply with these terms. 